\title{
Clinical deficiencies in infant feeding
}

Pilar Torre*

Health Care Department, Health and Society Area, Universidad Autónoma Metropolitana Unidad Xochimilco, Mexico City, Mexico

\begin{abstract}
The way in which two clinical procedures related to infant feeding are carried out in medical consultations for children younger than six months in a health center in Mexico City is analyzed. The first one refers to infants' anthropometric measurement, and the second, to feeding modalities' identification. Corrective actions are required based on the quality of children's health care in the public sector.
\end{abstract}

KEY WORDS: Infant feeding. Anthropometry. Feeding modality.

\section{Deficiencias en la labor clínica relacionada con la alimentación infantil}

\section{Resumen}

Se analiza la forma como se llevan a cabo dos procesos clínicos relacionados con la alimentación infantil en las consultas médicas de niños menores de seis meses atendidos en un centro de salud de la Ciudad de México. El primero se refiere a la medición antropométrica de los infantes y el segundo, a la identificación de las modalidades alimentarias. Se requieren acciones correctivas en función de la calidad en la atención a la salud infantil en el sector público.

PALABRAS CLAVE: Alimentación infantil. Antropometría. Modalidad alimentaria.

\section{Introduction}

When analyzing the role of public health services with regard to infant feeding through a more far-reaching ethnographic case study, we found two problems related to infant feeding, observed in medical consultation for children younger than six months in a health center of Mexico City: low quality of anthropometry and inadequate identification of infant feeding modalities. ${ }^{1}$

Infant feeding can be defined as human offspring's passage from a single source of nutrition, breast milk -or some substitute- during the first months, to the varied diet of each family, a process that takes approximately two years, when weaning or its equivalent occurs as bottle-feeding is discontinued. Various elements of mothers and their babies' social, cultural, family and personal life point towards different modalities. A significant element is contact with health services, the information on infant nutrition that is provided in postnatal medical consultations at health centers.

The World Health Organization proposes exclusive breastfeeding (EBF) up to six months of age, with continued breastfeeding along with complementary foods up to 24 months of age or longer. ${ }^{2,3}$

The decline in the practice of breastfeeding (BF) in Mexico has been documented for decades. ${ }^{4}$ In 2015, the National Survey of Boys, Girls and Women indicated that $94.9 \%$ of children younger than two years had been breastfed some time; $51 \%$ of women breastfed the newborn within the first postpartum
Correspondence:

*Pilar Torre

E-mail: ptorre@ correo.xoc.uam.mx
Gac Med Mex. 2020;156:454-457 Contents available at PubMed www.gacetamedicademexico.com 0016-3813/@ 2020 Academia Nacional de Medicina de México, A.C.. Published by Permanyer. This is an open access article under the CC BY-NC-ND license (http://creativecommons.org/licenses/by-nc-nd/4.0/). 
hour; the prevalence of EBF in children younger than six months was $30.8 \%$; BF mean duration was 10.9 months; $66.4 \%$ of children younger than two years used a bottle on the previous day; and only $39 \%$ received age-appropriate breastfeeding. ${ }^{5}$ The consequences associated with these figures represent challenges for public policies. This document aims to contribute elements for social discussion on nurturance, reproduction and health services, and to promote a dialogue between the academy and medical practice.

\section{Anthropometry deficiencies}

The first clinical deficiency was identified in the acquisition, recording and interpretation of children's anthropometry, which basically refers to age, gender, weight and length of babies, and which is related to nutritional diagnosis and infant growth. There are no standardized procedures to carry out measurements. ${ }^{6}$ Gender is assigned at birth. Age is asked by doctors on repeated occasions. Generally, measurements were carried out by nursing staff prior to consultation. Babies were weighed naked or dressed, even with blankets and shoes; on an appropriate scale, or held by the mother on an adult scale, with her weight being subtracted to obtain the baby's weight. Only one office had an infantometer, which is the instrument to measure length; height was measured with a flexible measuring tape running across the baby's body, on the examination table, in parallel to a measuring tape placed on the handrail; head and foot pieces could have been used or not. It was common for the figures not to be written down immediately and for numerical mistakes to be made.

Several doctors showed difficulty to understand the scope and relationship of infant nutritional status indicators: weight-for-age, weight-for-length and lengthfor-age. As reference, some doctors used the Control of the Healthy Child program charts, others, a processed food poster (Gerber ${ }^{\circledR}$, Nestlé), others, their own parameters, with a few more declaring themselves incompetent for interpreting the information.

During the observation period, the World Health Organization anthropometric standards arrived at the health center. No presentation or training took place. It was assumed that everyone knew how anthropometry is carried out and that it was correctly performed; however serious deficiencies in its quality and scope were observed.
Table 1. Infant feeding modalities in $\mathbf{2 0}$ cases

\begin{tabular}{|l|c|}
\hline Modality & Cases (n) \\
\hline Exclusive breastfeeding & 6 \\
\hline Breastfeeding and water & 2 \\
\hline Breastfeeding and formula & 4 \\
\hline Breastfeeding and varied feeding & 3 \\
\hline Breastfeeding, formula and varied feeding & 2 \\
\hline Formula and varied feeding & 3 \\
\hline Total & 20 \\
\hline
\end{tabular}

\section{Identification of feeding modalities}

The other clinical deficiency concerns infant feeding modalities identification. In medical consultations, doctors asked the mothers what did the baby eat or something similar. On two occasions, the doctor did not ask and only prescribed the nutritional model to follow. With the maternal answers, the consultation modality was defined for each case.

In post-consultation interviews, the mothers were asked what the baby had eaten the day before, and the interview modality was designated. At least six infant feeding modalities were identified (Table 1). When the consultation modality was compared with the interview modality, a level of agreement of $50 \%$ was found (Table 2). This level of accuracy is not sufficient to understand the feeding patterns in all their dimension or to clinically address BF. ${ }^{1}$

Infant formulas were used since hospital stay for delivery care, as observed in cases 1 and 2. EBF was concentrated in the group of up to 10 weeks of age; thereafter, the modalities were diversified up to a varied diet, mostly with BF and formula. Of the 20 mothers, 17 offered BF, two more had tried for two months, but on the day of the interview they were no longer breastfeeding; in addition, a premature infant was never breastfed. That is, 19 of the 20 mothers did breastfed; six of them had succeeded with EBF on the consultation day; two more, in combination with water, and nine more combined BF with infant formula and various foods. Medical accuracy to identify infant feeding modalities was low.

\section{Discussion}

At each consultation, infant feeding and nutrition was discussed. Anthropometric data are always 
Table 2. Infant feeding modalities. Agreement between data obtained in consultation and maternal interview

\begin{tabular}{|c|c|c|c|c|}
\hline \multirow[t]{2}{*}{ Case } & \multirow{2}{*}{$\begin{array}{c}\text { Age } \\
\text { (weeks) }\end{array}$} & \multicolumn{2}{|c|}{ Modality } & \multirow[t]{2}{*}{ Agreement } \\
\hline & & Consultation & Interview & \\
\hline 1 & 3 days & EBF & $\mathrm{BF}+\mathrm{F}$ & No \\
\hline 2 & 12 days & EBF & $B F+F+W$ & No \\
\hline 3 & 13 days & EBF & EBF & Yes \\
\hline 4 & 4 & EBF & EBF & Yes \\
\hline 5 & 4 & $\mathrm{BF}+\mathrm{F}$ & $\mathrm{BF}+\mathrm{F}$ & Yes \\
\hline 6 & 4 & EBF & $B F+W$ & No \\
\hline 7 & 5 & EBF & EBF & Yes \\
\hline 8 & 7 & $\mathrm{BF}+\mathrm{F}^{*}$ & $\mathrm{BF}+\mathrm{F}$ & Yes \\
\hline 9 & 8 & $\mathrm{BF}+\mathrm{F}^{*}$ & $B F+W$ & No \\
\hline 10 & 8 & EBF & EBF & Yes \\
\hline 11 & 8 & EBF & EBF & Yes \\
\hline 12 & 9 & $\mathrm{BF}+\mathrm{F}$ & $\mathrm{F}+$ tea + oral rehydration solution $+\mathrm{W}$ & No \\
\hline 13 & 10 & EBF & EBF & Yes \\
\hline 14 & 13 & $\mathrm{BF}+\mathrm{F}$ & $\mathrm{BF}+\mathrm{F}+\mathrm{W}+$ tea & No \\
\hline 15 & 14 & $\mathrm{BF}+$ whole milk + oatmeal & $\mathrm{BF}+$ whole milk + oatmeal + tea $+\mathrm{W}$ & No \\
\hline 16 & 14 & $B F+F$ & $\mathrm{BF}+\mathrm{F}$ & Yes \\
\hline 17 & 22 & $F+$ tea $+W$ & $F+$ tea $+W+$ commercial baby food + banana & No \\
\hline 18 & 22 & F + apple + banana & $F+$ fruit + vegetables $+W$ & No \\
\hline 19 & 23 & $\begin{array}{l}\mathrm{BF}+\mathrm{F}+\text { chicken broth + rice + chayote }+ \text { carrot }+ \\
\text { zucchini + potato + banana + apple }+ \text { pear }+W\end{array}$ & $\begin{array}{l}\mathrm{BF}+\mathrm{F}+\text { chicken broth }+ \text { rice }+ \text { chayote }+ \text { carrot }+ \\
\text { zucchini + potato + banana }+ \text { apple }+ \text { pear }+W\end{array}$ & Yes \\
\hline 20 & $24^{\star *}$ & $\mathrm{BF}+$ guava + mango + baby food & $\mathrm{BF}+$ carrot $+\mathrm{W}+$ tea & No \\
\hline
\end{tabular}

present and are essential. Anthropometry quality was poor, and medical personnel capability to diagnose the nutritional status was limited, which deserves health authorities' attention.

The medical question "what does the baby eat?" is routine and superficial. In two cases, it was not formulated. Infant feeding modalities descriptive accuracy indicates that doctors do not ask the relevant questions. Case 2 illustrates that the question has an answer, but the feeding modality is not described: the doctor asked the mother if she had been breastfeeding, and she answered affirmatively; actually, the modality was BF, formula and foods at the baby's $12^{\text {th }}$ day of life; however, the doctor assumed that the feeding modality was EBF.
Few physicians clarify the relationship between breast milk demand and production, or how to achieve a good latch between a suckling baby and a mother who produces and offers milk through breastfeeding. Case 8, of seven weeks of age, is extreme: on one hand, the doctor instructed the mother to feed the baby exclusively on breast milk until four months of age, but on the other, he indicated that if she wasn't producing enough breast milk, she could feed the baby with formula.

There are arguments to substantiate the existence of serious problems in the scope of medical practices and prescriptions about infant feeding, which require a review in light of current knowledge and international consensuses. The problems that were identified reflect archaic, medicalized and insufficient notions 
about infant feeding for offering counseling to the population that attends postnatal consultations, which can be considerably improved with information, training and political will.

The situation in Mexico is the result of medical, social and family practices based on the "culture of bottle-feeding", which is referred to by the Innocenti Declaration and that must be recognized and described in order to oppose arguments in favor of a "culture of breastfeeding". Regarding the daily decisions that infant feeding practices entail, mothers interact with health services, where recommendations on medicalized dietary normativity are expressed. We can argue that great ignorance prevails regarding BF conditions and requirements, particularly in its exclusive modality, and the guidance to carry it out. The World Health Organization has high-impact training models. ${ }^{8}$ Some time ago, the General Hospital of Mexico operated a BF training center, which could be a precedent for nation-wide actions.

\section{Necessary note}

In this text, the term doctor is used without gender distinction, in the sense of describing the professional function at medical consultation, rather than in the sense of naming the subject, male or female, who exercises it. Something similar occurs with the term baby.

\section{Acknowledgements}

To Monserrat Salas, for the theoretical-methodological dialogue, and for her friendship. To Adriana
Chávez, for her efficacy. To Universidad Autónoma Metropolitana Unidad Xochimilco, for its generosity and environment.

\section{Conflict of interests}

The author declares that she has no conflicts of interest.

\section{Funding}

The research was carried out with the annual budget for research projects granted by Universidad Autónoma Metropolitana Unidad Xochimilco (approximately USD 800).

\section{References}

1. Torre P. Epistemología de la alimentación infantil en los servicios de primer nivel de atención a la salud. Estudio de casos en México. [Doctoral thesis]. Basque Country: Universidad del País Vasco; 2015.

2. Organización Mundial de la Salud. Estrategia Mundial para la Alimentación del Lactante y del Niño Pequeño. Suiza: Organización Mundial de la Salud; 2001

3. World Health Organization. Optimal duration of exclusive breastfeeding. A systematic review. Switzerland: World Health Organization; 2002.

4. Ysunza A. El abandono de la lactancia materna en México I: tendencias recientes. Rev Invest Clín. 1986; 38S:97-102.

5. Fondo de las Naciones Unidad para la Infancia/Instituto Nacional de Salud Pública. Encuesta Nacional de Niñas, Niños y Mujeres 2015. Informe final. Mexico: UNICEF/INSP; 2016.

6. Peláez $M$, Torre $P$, Ysunza $A$. Elementos prácticos para el diagnóstico de la desnutrición. Mexico: Instituto Nacional de Ciencias Médicas y Nutrición Salvador Zubirán; 1993.

7. World Health Organization/United Nations International Children's Emergency Fund. The Innocenti Declaration. Breastfeeding in the 1990's. A Global Initiative. Italy: WHO/UNICEF; 1990.

8. Organización Mundial de la Salud/Fondo de las Naciones Unidas para la Infancia. Consejería en lactancia materna. Curso de capacitación. Manual del participante. Suiza: OMS/UNICEF; 1993. 